\title{
Myocardial injury in coronary artery bypass grafting: On-pump versus off-pump comparison by measuring high-sensitivity C-reactive protein, cardiac troponin I, heart-type fatty acid-binding protein, creatine kinase- $M B$, and myoglobin release
}

Ujjwal K. Chowdhury, MCh, Diplomate NB, ${ }^{a}$ Vishwas Malik, DM, ${ }^{\mathrm{b}}$ Rakesh Yadav, DM, ${ }^{\mathrm{c}}$ Sandeep Seth, DM, Lakshmy Ramakrishnan, PhD, ${ }^{d}$ Mani Kalaivani, MSc (Biostatistics), ${ }^{\text {e }}$ Srikrishna M. Reddy, MS, ${ }^{\text {a }}$

Ganapathy K. Subramaniam, MCh, ${ }^{a}$ Raghu Govindappa, $\mathrm{MS}^{\mathrm{a}}{ }^{\text {and }}$ ad Mava Kakani, MD ${ }^{\mathrm{b}}$

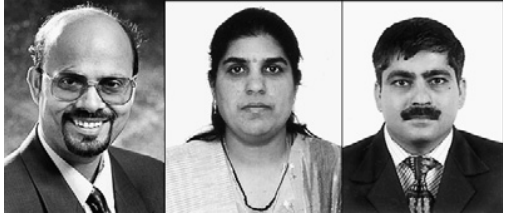

Drs Chowdhury, Ramakrishnan, and Malik (left to right)

B Supplemental material is available online.

Objectives: We sought to investigate the release pattern of different cardiac biomarkers (high-sensitivity C-reactive protein, cardiac troponin I, heart-type fatty acid-binding protein, creatine kinase-MB, and myoglobin) and to establish the diagnostic discrimination limits of each marker protein to evaluate perioperative myocardial injury in patients undergoing coronary artery bypass grafting with or without cardiopulmonary bypass.

Methods: Fifty patients were randomly assigned to on-pump or off-pump coronary artery bypass grafting. All cardiac biomarkers were measured in serial venous blood samples drawn before heparinization in both groups and after aortic unclamping at 1,2, 4, 8, 24,48 , and 72 hours in the on-pump group. In the off-pump group samples were taken after the last distal anastomosis and at same time intervals as in the on-pump group.

Results: The total amount of heart-type fatty acid-binding protein, cardiac troponin I, and high-sensitivity C-reactive protein released was significantly higher in the onpump group than in the off-pump group. Receiver operating characteristic curve analysis of cardiac biomarkers indicated cardiac troponin I and heart-type fatty acid-binding protein as the superior diagnostic discriminators of myocardial injury, with an optimal cutoff value of greater than $0.92 \mathrm{ng} / \mathrm{mL}$ (area under the curve, 0.95 [95\% CI, 0.88-1.00]; sensitivity, 92\%; specificity, 92\%; likelihood ratio [+], 11.50) and greater than $6.8 \mathrm{ng} / \mathrm{mL}$ (area under the curve, 0.94 [95\% CI, 0.881.00]; sensitivity, $88 \%$; specificity, $88 \%$; likelihood ratio [+], 7.33), respectively. Lo-

From the Departments of Cardiothoracic and Vascular Surgery, ${ }^{\mathrm{a}}$ Cardiac Anaesthesia, ${ }^{\mathrm{b}}$ Cardiology, ${ }^{\mathrm{c}}$ Cardiac Biochemistry, ${ }^{\mathrm{d}}$ and Biostatistics, ${ }^{\text {e }}$ All India Institute of Medical Sciences, New Delhi, India.

Received for publication July 20, 2007; revisions received Dec 17, 2007; accepted for publication Dec 27, 2007.

Address for reprints: Ujjwal K. Chowdhury, $\mathrm{MCh}$, Diplomate NB, Department of Cardiothoracic and Vascular Surgery, All India Institute of Medical Sciences, New Delhi-110029, India (E-mail: ujjwalchow@rediffmail.com or ujjwalchowdhury@gmail.com).

J Thorac Cardiovasc Surg 2008;135:1110-9 0022-5223/\$34.00

Copyright (C) 2008 by The American Association for Thoracic Surgery

doi:10.1016/j.jtcvs.2007.12.029 gistic regression analysis revealed that patients with increased cardiac troponin I levels of greater than $0.92 \mathrm{ng} / \mathrm{mL}$ and heart-type fatty acid-binding protein levels of greater than $6.8 \mathrm{ng} / \mathrm{mL}$ were at 132.25 (95\% confidence interval, 17.141020.49) times and 53.77 (95\% confidence interval, 9.76-296.12) times higher risk of myocardial injury after on-pump coronary artery bypass grafting.

Conclusions: Off-pump coronary artery bypass grafting provides better myocardial protection than on-pump coronary artery bypass grafting. Cardiac troponin I and heart-type fatty acid-binding protein, but not high-sensitivity C-reactive protein, served as superior diagnostic discriminators of perioperative myocardial damage after on-pump coronary artery bypass grafting.

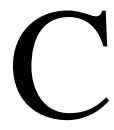
oronary artery bypass grafting (CABG) surgery with cardiopulmonary bypass (CPB) is both safe and effective. Nevertheless, the use of CPB and cardioplegic arrest are associated with myocardial stunning and substantial morbidity. ${ }^{1}$ During the past decade, with the introduction of better stabilizing systems, such as the 


\author{
Abbreviations and Acronyms \\ ACT = activated clotting time \\ AUC = area under the curve \\ $\mathrm{CABG}=$ coronary artery bypass grafting \\ $\mathrm{CI}=$ confidence interval \\ $\mathrm{CK}-\mathrm{MB}=$ creatine kinase-MB \\ $\mathrm{CPB}=$ cardiopulmonary bypass \\ cTn-I = cardiac troponin I \\ hFABP $=$ heart-type fatty acid-binding protein \\ hs-CRP $=$ high-sensitivity C-reactive protein \\ ICU = intensive care unit \\ MRI = magnetic resonance imaging \\ ROC $=$ receiver operating characteristic
}

octopus and the starfish, and other technical improvements, there has been a revival of interest in performing CABG on a beating heart. During this time, off-pump CABG has been audited against on-pump CABG in many observational, case-matched, and prospective randomized studies. ${ }^{1-3}$ The published literature documents reduced blood loss and transfusion requirements, reduction of postoperative morbidity, organ dysfunction, and a more favorable outcome in selected high-risk patients revascularized by using the off-pump technique. $^{1-3}$

Myocardial ischemia during cardiac surgery results in functional and structural changes and ultimately in release of proteins from injured cardiac myocytes. ${ }^{1-3}$ The release pattern of different proteins varies, as does their cardiospecificity. ${ }^{4}$ Creatine kinase and its isoform, creatine kinase-MB (CK-MB), have been the most frequently used tools in the diagnosis of myocardial ischemia. ${ }^{5}$ In recent years, structural myofibrillar proteins, such as troponin $\mathrm{T}$ and troponin $\mathrm{I}$, along with their cardiospecific isoform, heart-type fatty acid-binding protein (hFABP), high-sensitivity C-reactive protein (hs-CRP), creatine kinase-MB (CK-MB), and myoglobin, have entered the clinical field and have been used in daily routine and in scientific clinical research. However, the time delay between the operative damage and detection of a measurable amount of protein in peripheral blood remains a major concern, rendering difficulty in the rapid evaluation of the degree of myocardial injury. Second, markers with improved sensitivity and specificity are required for accurate and reliable information concerning myocardial biochemistry.

The aims of this prospective study were (1) to investigate the release of kinetics of different cardiac biochemical markers (hs-CRP, cardiac troponin I [cTn-I], hFABP, CK$\mathrm{MB}$, and myoglobin) and their relevance to myocardial injury in patients undergoing beating- and arrested-heart revascularization and (2) to measure the sensitivity, specificity, and the likelihood ratio $(+)$ of individual cardiac markers to establish the diagnostic discrimination limits of each marker protein to evaluate perioperative myocardial injury.

\section{Materials and Methods \\ Criteria for Patient Selection}

This study conforms to the principles outlined in the declaration of Helsinki. Fifty patients (41 male patients) scheduled to undergo first elective CABG between June 2004 and March 2006 were enrolled in this prospective randomized trial after obtaining the institutional ethics committee's approval and written informed consent from each patient. All patients were eligible for both on-pump and offpump revascularization and were randomly distributed into one of 2 groups: (1) the on-pump group $(\mathrm{n}=25)$, in which the coronary revascularization was done with the use of CPB and moderate hypothermia, and (2) the off-pump group $(n=25)$, in which surgical intervention was performed without the use of CPB. Their demographic and clinical profiles are depicted in Table E1. There was no significant difference between the 2 groups in age, sex, weight, height, comorbidities, and medication. Cardiac catheterization data were comparable in 2 population groups regarding the number of diseased vessels. None of the patients received thrombolytic agents.

Patients were excluded if any of the following criteria were present: (1) emergency cardiac operations, (2) preoperative myocardial infarction within the last 2 weeks or ongoing myocardial infarction, (3) treatment with fibrinolytic agents within 48 hours before the operation, (4) patients undergoing cardiac reoperations, (5) poor ventricular function (ejection fraction, $<0.30$ ), (6) concomitant valvular heart disease, (7) unstable angina, (8) renal disease, (9) chronic obstructive airway disease, (10) steroid therapy, (11) hepatic disease (as indicated by aspartate aminotransferase or alanine aminotransferase levels of greater than 2 times the upper limit of normal or by bilirubin levels of greater than 1.5 times the upper limit of normal), and (12) severe coagulation abnormalities.

\section{Anesthetic Technique}

All patients received a standardized anesthetic technique. Premedication included morphine $(0.1 \mathrm{mg} / \mathrm{kg})$ and promethazine $(0.25 \mathrm{mg} /$ $\mathrm{kg}$ ), both injected intramuscularly 1 hour before the operation. Anesthesia was induced with midazolam $(0.2 \mathrm{mg} / \mathrm{kg})$, fentanyl $(2-4$ $\mu \mathrm{g} / \mathrm{kg}$ ), thiopentone sodium (2-5 mg/kg), and rocuronium (0.6$0.9 \mathrm{mg} / \mathrm{kg}$ ) and maintained with isoflurane (end-tidal concentration, $<1$ minimum alveolar concentration), fentanyl $\left(2 \mu \mathrm{g} \cdot \mathrm{kg}^{-1} \cdot \mathrm{h}^{-1}\right)$, midazolam $\left(0.04 \mathrm{mg} \cdot \mathrm{kg}^{-1} \cdot \mathrm{h}^{-1}\right)$, and pancuronium $(0.8 \mathrm{mg} \cdot$ $\left.\mathrm{kg}^{-1} \cdot \mathrm{h}^{-1}\right)$. Perioperative antibiotic prophylaxis was provided with $1 \mathrm{~g}$ of injection cefotaxime administered intravenously.

\section{Heparin and Protamine Management}

In the on-pump group heparin was administered at a dose of $3 \mathrm{mg} / \mathrm{kg}$ to achieve a target activated clotting time (ACT) of 480 seconds or greater before commencement of $\mathrm{CPB}$. The ACT was monitored during the bypass period (every 30 minutes), and an additional 0.5 $\mathrm{mg} / \mathrm{kg}$ heparin was administered, if required. In the off-pump group heparin $(1.5 \mathrm{mg} / \mathrm{kg})$ was administered before the start of the first anastomosis or before the division of the left internal thoracic artery. The target ACT in this group was 250 to 300 seconds. Protamine sulfate was used to reverse the effect of heparin at a dose ratio of 1.5:1 at the end of the operation. 


\section{Surgical Techniques}

On-pump group. All patients in this group underwent revascularization during CPB by using aortoatrial cannulation and moderate systemic hypothermia. The extracorporeal device consisted of a roller pump, a reservoir, and a membrane oxygenator. The prime of the circuit consisted of $1500 \mathrm{~mL}$ of Ringer's lactate containing 0.5 $\mathrm{g} / \mathrm{kg}$ of mannitol and $5000 \mathrm{IU}$ of heparin. The pump flows were adjusted to maintain a cardiac index of greater than $2.4 \mathrm{~L} \cdot \mathrm{min}^{-1}$. $\mathrm{m}^{-2}$. Aprotinin, $\varepsilon$-aminocaproic acid, or tanexamic acid were not administered to any patient in the on-pump group. Myocardial protection was achieved by means of anterograde intermittent administration of a cold blood St Thomas-based cardioplegic solution both through the aortic root and through the graft after completion of each distal anastomosis. Ischemic preconditioning or retrograde cardioplegia was not used on any patient.

After distal anastomosis and once the left internal thoracic artery was unclamped, warm reperfusion composed exclusively of $37^{\circ} \mathrm{C}$ oxygenated blood was administered through a multiperfusion catheter with a constant flow rate of between 200 and $500 \mathrm{~mL} / \mathrm{min}$ to minimize myocardial ischemia.

Off-pump group. In the off-pump group colloids were administered, and position changes and gravity support (Trendelenburg and right and left table rotation) were used to stabilize patients' hemodynamics and to maintain a controlled systolic arterial pressure between 120 and $140 \mathrm{~mm} \mathrm{Hg}$ to optimize coronary perfusion. The distal anastomoses were performed first. Single aortic side clamping was performed to minimize the risk of aortic trauma during multiple proximal anastomoses. The systolic blood pressure was decreased to about 80 to $90 \mathrm{~mm} \mathrm{Hg}$ for application of the side clamp and to minimize the risk of aortic injury and atheroembolization. This level of systemic arterial pressure was maintained during the time that the side-biting clamp was placed on the aorta for the proximal anastomosis. Lesions of the left anterior descending coronary artery were bypassed with a left internal thoracic artery pedicle graft, where feasible. Target artery immobilization and regional myocardial control was achieved through a commercially available Octopus III stabilizer-suction system (Octopus Tissue Stabilizer; Medtronic, Inc, Eden Prairie, Minn). Intracoronary shunts were used if there was (1) excessive bleeding at the site of arteriotomy obscuring adequate visualization despite using a mister blower, (2) electrocardiographic evidence of new-onset regional ischemia, or (3) ventricular dysfunction to provide distal flow until completion of the anastomosis.

\section{Biochemical Analysis}

Blood samples were collected from each patient after sternotomy and before systemic heparinization, 1 hour after declamping (or after completion of last distal anastomosis in off-pump group), and then at 2, 4, 8, 24, 48, and 72 hours in both groups. Samples were immediately cooled to $4{ }^{\circ} \mathrm{C}$ and centrifuged at $3000 \mathrm{rpm}$ for 10 minutes at $4^{\circ} \mathrm{C}$. Serum was stored at $-70^{\circ} \mathrm{C}$ until assay. Serum levels of hFABP were measured by means of enzyme-linked immunosorbent assay (Hycult Biotechnology, Uden, The Netherlands), and levels of CK-MB were measured by using the photometric method (Diasys Diagnostic System GmbH, Holzheim, Germany). cTn-I and myoglobin levels were measured by using immunometric technology (Diagnostic Products Corp, Los Angeles, Calif). Ultrasensitive C-reactive protein levels were mea- sured by using diagnostic kits from Spinreact, SA, Citra Santa Coloma (Sant Esteve Debas [GI], Spain).

\section{Clinical Variables}

In addition to biochemical measurements, we recorded patients' needs for inotropic agents, duration of ventilatory support, and intensive care unit (ICU) stay. A patient's inotropic requirement was classified as none, mild (dopamine, $\leq 5 \mu \mathrm{g} \cdot \mathrm{kg}^{-1} \cdot \min ^{-1}$ ), or moderate (dopamine, $>5 \mu \mathrm{g} \cdot \mathrm{kg}^{-1} \cdot \mathrm{min}^{-1}$; dobutamine, $>5$ $\mu \mathrm{g} \cdot \mathrm{kg}^{-1} \cdot \min ^{-1}$; or adrenaline, $\left.<0.1 \mu \mathrm{g} \cdot \mathrm{kg}^{-1} \cdot \mathrm{min}^{-1}\right)$.

Twelve-lead electrocardiographic recordings were performed preoperatively, at 2 hours postoperatively, and then daily for at least the first 3 postoperative days. All patients had continuous electrocardiographic monitoring until they were discharged from the ICU.

A single cardiologist, who was blinded to the study, performed transthoracic 2-dimensional echocardiography in all patients to evaluate left ventricular function at 8 hours postoperatively and again before discharge. Left ventricular function was defined as moderate (ejection fraction, $0.30-0.50$ ) or good (ejection fraction, $>0.50$ ).

\section{Definitions}

Perioperative myocardial injury. Perioperative myocardial infarction represents the most severe complication at the end of an adverse cascade, usually initiated by episodes of prolonged subendocardial ischemia, which might occur as a reversible or irreversible event and is no longer viewed as a binary event. It is now held that there is a spectrum of myocardial injury characterized by increasing release of cardiac biomarkers to a full-blown picture of myocardial infarction. ${ }^{1-4,6,7}$ The reported incidence of perioperative myocardial injury after $\mathrm{CABG}$ has varied considerably, ranging between $5 \%$ and $20 \%$, partly as a result of the use of different definitions and diagnostic criteria. ${ }^{1-4}$ The pathogenesis of perioperative myocardial injury after $\mathrm{CABG}$ is based on a variety of graft-related and non-graft-related mechanisms. The graft-related reasons are graft occlusion, graft kinking or overstretching, subtotal anastomotic stenosis, or graft spasm. Non-graft-related causes include direct myocardial trauma by means of surgical manipulation, inadequate cardioplegic perfusion and myocardial protection, incomplete revascularization, and distal coronary microembolization caused by surgical manipulation. ${ }^{1-14}$ The gap between reversible myocardial ischemia and definite death of myocardial cells of a major area might be linked by appropriate assessment of minor myocardial cellular injury, which could help to prevent myocardial infarction. ${ }^{1-14}$

For uniformity with other studies, perioperative myocardial injury was considered to be present in the presence of one of the following criteria: (1) appearance of a new and persistent Q-wave with a duration of greater than $40 \mathrm{~ms}$ in at least 2 adjacent leads; (2) disappearance of an R-wave or $25 \%$ reduction of R-waves in 2 leads; (3) appearance of ST-segment deviations at the J-point in 2 or more contiguous leads with cutoff points of greater than $0.2 \mathrm{mV}$ in leads $\mathrm{V} 1, \mathrm{~V} 2$, or $\mathrm{V} 3$ and greater than $0.1 \mathrm{mV}$ in other leads or $\mathrm{T}$-wave abnormalities in 2 or more continuous leads; (4) appearance of a new-onset left bundle branch block; (5) new and persistent wallmotion abnormalities on transesophageal echocardiography; and (6) requirement of inotropic support to maintain stable hemodynamics as stated in the absence of mechanical external compression. 
Low output syndrome after coronary artery bypass. Low output syndrome after CABG was diagnosed if the patient required inotropic support in the ICU, required intra-aortic balloon assistance postoperatively, or both. ${ }^{1-4,15}$ It was diagnosed if the patient required inotropic support (dopamine, $4-10 \mu \mathrm{g} \cdot \mathrm{kg}^{-1} \cdot \mathrm{min}^{-1}$; dobutamine, $5-10 \mu \mathrm{g} \cdot \mathrm{kg}^{-1} \cdot \min ^{-1}$; epinephrine, $0.01-0.1 \mu \mathrm{g}$. $\mathrm{kg}^{-1} \cdot \mathrm{min}^{-1}$; milrinone, $50 \mu \mathrm{g} / \mathrm{kg}$ intravenous bolus followed by $0.375-0.75 \mu \mathrm{g} \cdot \mathrm{kg}^{-1} \cdot \mathrm{min}^{-1}$ ), either isolated or in combination, in the operating room or in the ICU to maintain stable hemodynamics in the absence of mechanical external compression after correction of all electrolytes or blood gas abnormalities and after adjusting the preload to its optimal value. ${ }^{1-4,15}$

Low output syndrome was also diagnosed if there was an increasing requirement of the abovementioned inotropes along with afterload reduction with sodium nitroprusside. Patients who received less than $4 \mu \mathrm{g} \cdot \mathrm{kg}^{-1} \cdot \mathrm{min}^{-1}$ of dopamine to increase renal perfusion were not considered to have low output syndrome. ${ }^{1-4,15}$

Generally under the definition of low output syndrome after $\mathrm{CABG}$, an integration of relevant clinical, laboratory, and bedside echocardiographic criteria were used. The criteria for diagnosis were cold extremities, absent pedal pulses, decreased toe temperature, reduced systolic pressure $(<90 \mathrm{~mm} \mathrm{Hg})$, decreased cardiac output $\left(<2.2 \mathrm{~L} \cdot \mathrm{min}^{-1} \cdot \mathrm{m}^{-2}\right)$ or at least 30 minutes in the operating room or ICU, impaired renal function and oliguria $(<1.0 \mathrm{~mL}$. $\left.\mathrm{kg}^{-1} \cdot \mathrm{h}^{-1}\right)$, metabolic acidosis, increased serum lactate levels $(\geq 2$ $\mathrm{mmol} / \mathrm{L}$ for greater than 2 hours), low mixed venous oxygen saturation $(\leq 50 \%)$, and blunt sensorium.

\section{Statistical Analysis}

Statistical analysis was carried out with STATA 9.0 software (College Station, Tex). Continuous and interval-related data were presented as means \pm standard deviation and medians (ranges), whereas categorical variables were presented as frequency distributions and percentages. At each time point, the difference in the medians of all cardiac biomarker values between the on-pump and offpump procedures were compared by using the Wilcoxon rank sum test because the data were nonnormal and mean value was not the right measure. Within the group, the difference in the medians was compared by using Friedman 2-way analysis of variance.

A receiver operating characteristic (ROC) curve analysis was used to identify the discrimination limits for each of the cardiac biomarkers at each time point separately in predicting myocardial injury, taking the on-pump CABG group as the riskier group. The area under the ROC curve (95\% confidence interval [CI]), sensitivity, specificity, and the likelihood ratio were calculated to analyze the diagnostic value of each markers. ${ }^{16}$ Logistic regression was carried out to quantify the risk of myocardial injury at a specified time point after the operation in patients undergoing on-pump CABG by using each of the cardiac biomarkers.

Although ROC curves are usually used to evaluate and compare an operator or diagnostic test with a gold standard and to explore the tradeoffs between sensitivity and specificity for a test, the areas under the ROC curves are independent of both the cutoff point criteria (predicted probabilities) and the prevalence of outcomes. ${ }^{16}$ In this study ROC analysis was performed after calculating the sensitivity and specificity for all the values (cutoff point) of a particular cardiac biomarker. In this process of calculating sensitivity and specificity, neither of these was affected by extreme values or wide variations
(Table E5). Therefore we used these curves to provide an additional diagnostic tool to determine the discrimination limit for each of the cardiac biomarkers after on-pump CABG.

\section{Results}

There was no operative or hospital mortality for either the onpump or off-pump groups. There were no conversions from the off-pump to on-pump groups.

In the on-pump group CPB time was $106.8 \pm 30.6 \mathrm{~min}-$ utes, and aortic crossclamp time was $52.8 \pm 17.5$ minutes. The number of distal anastomoses performed in the 2 groups was marginally different and did not reach statistical significance $(3.2 \pm 0.62$ vs $3.1 \pm 0.60, P=.56)$. Despite following a standardized protocol for the length of ventilation and institution of inotropes in the setting of low output syndrome, significant differences were observed between the on-pump and off-pump CABG groups in duration of mechanical ventilation $(18.60 \pm 3.62$ vs $12.80 \pm 2.42$ hours, $P<.0001)$ and ICU stay (41.28 \pm 0.62 vs $35.80 \pm 1.8$ hours, $P<.001$; Table E2).

Four $(16 \%)$ patients in the on-pump group and $18(72 \%)$ in the off-pump group required no inotropic drug support. Four $(16 \%)$ patients in the on-pump group required moderate inotropic support because of low output syndrome, whereas no patient required such support in the off-pump group (Table E3). There was no perioperative myocardial infarction in either group, as defined by electrocardiographic criteria or inhospital death. The postoperative course was uneventful in all patients. There was transient moderate impairment of left ventricular ejection fraction ranging between 0.30 and 0.50 at 8 hours in all but 1 patient who underwent on-pump CABG (96\% on-pump vs $68 \%$ off-pump, $P=.023$ ). However, there was no noticeable difference in this regard at discharge (Table E3).

\section{Time Course of Median Concentration of Biomarkers}

The median values of each marker protein increased from a baseline concentration preoperatively to a postoperative peak, indicating myocardial damage of a certain degree in all cases. The total amount of biomarkers released in both groups has not been considered for comparative evaluation of myocardial injury because an initially increased value can take a few days to resolve and would be counted or added to the total amount as high on multiple occasions.

For each sample drawn, hs-CRP concentrations were significantly higher in the on-pump group than in the off-pump group at 4 hours $(P=.04)$, and 8 hours $(P=.009)$ only (Table E4, $A$, and Figure 1).

For each sample drawn, cTn-I concentrations were significantly higher in the on-pump group than in the off-pump group at 1 hour $(P<.0001), 2$ hours $(P<.0001)$, 4 hours $(P<.0001), 8$ hours $(P<.0001)$, and 24 hours $(P=.04)$. However, cTn-I concentrations were comparable at 48 and 72 hours (Table E4, $B$, and Figure 2). 


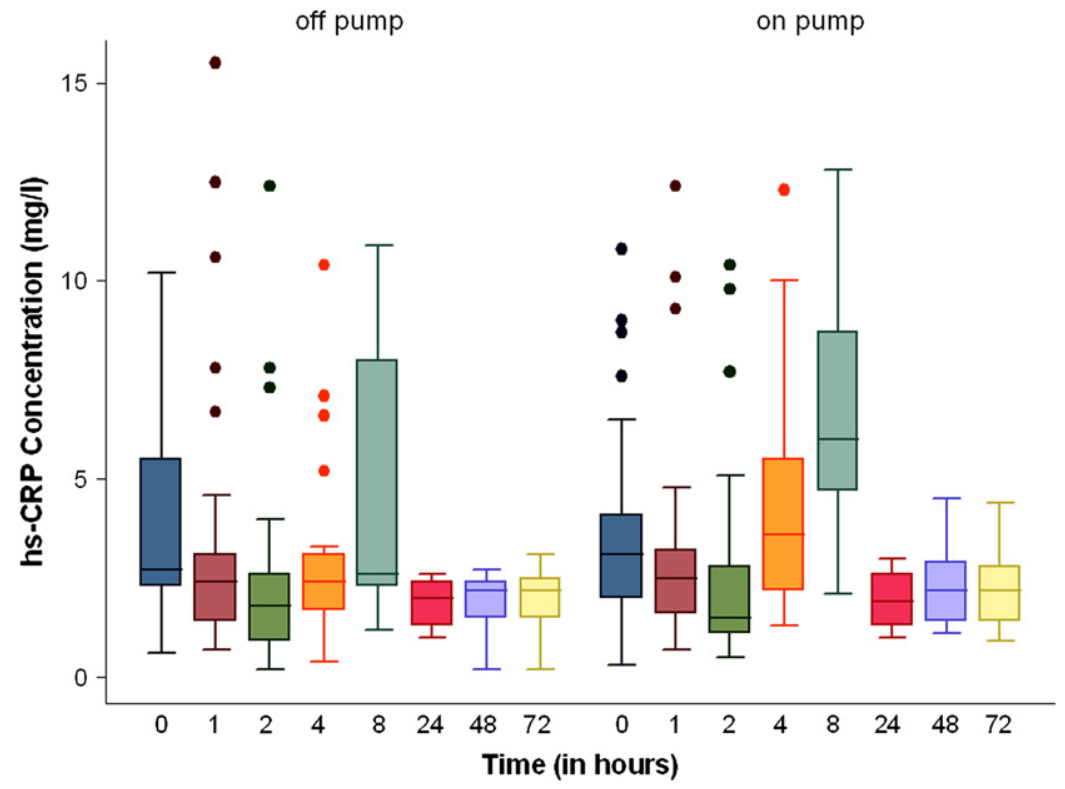

Figure 1. Release kinetics of high-sensitivity Creactive protein (hs-CRP) concentrations broken down by surgical procedure (on-pump vs offpump) at baseline (0), 1 hour, 2 hours, 4 hours, 8 hours, 24 hours, 48 hours, and 72 hours, respectively. Dots represent the outliers that were outside the calculated range, possibly because of biologic variability. The 2 measurements differed significantly $(P=.04)$. The hs-CRP concentration was significantly higher in the on-pump group than in the off-pump group at 4 hours $(P=.04)$ and 8 hours $(P=.009)$ only.
For each sample drawn, hFABP concentrations were significantly higher at 1 hour $(P<.0001), 2$ hours $(P=.001)$, 4 hours $(P=.0002), 8$ hours $(P=.0008), 24$ hours $(P=$ $.0002), 48$ hours $(P=.0004)$, and 72 hours $(P<.0001$; Table E4, $C$, and Figure 3 ).

The degree of CK-MB increase was significantly higher in the on-pump group at 1 hour $(P=.001), 2$ hours $(P=.005)$, and 4 hours $(P=.0008)$ only (Table E4, $D$, and Figure 4$)$.

For each sample drawn, myoglobin concentration was significantly higher only at 1 hour $(P=.001)$ and 2 hours $(P=$ .04 ) after surgical intervention in the on-pump group (Table E4, E, and Figure 5).
Diagnostic Performance of hsCRP, cTn-I, hFABP, CK-MB, and Myoglobin

To determine the optimal cutoff values and test characteristics of the abovementioned cardiac markers at every postoperative time point in patients undergoing on-pump $\mathrm{CABG}$, ROC analysis revealed the following.

cTn-I was the best diagnostic discriminator of myocardial injury, with an optimal cutoff value of greater than $0.92 \mathrm{ng} / \mathrm{mL}$ at 1 hour after aortic declamping (area under the curve [AUC], 0.95 [95\% CI, 0.88-1.0]; sensitivity, $92 \%$, specificity, 92\%; likelihood ratio $[+], 11.50$; Table E6 and Figure 6).

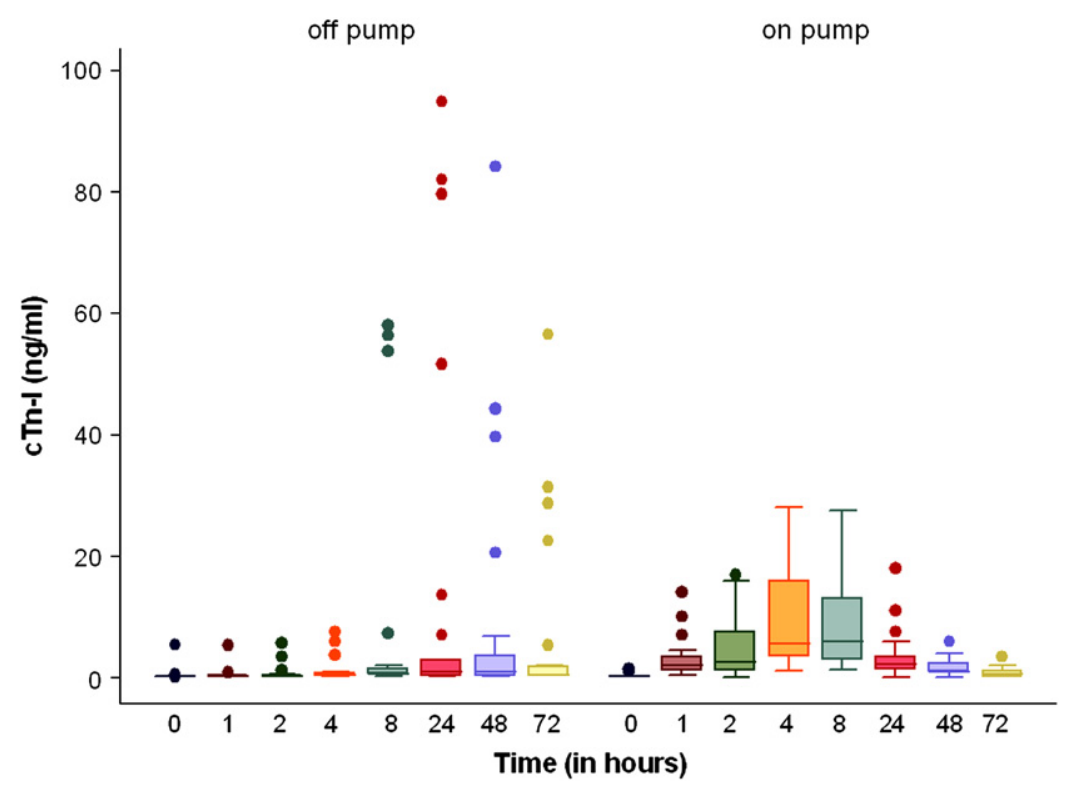

Figure 2. Release kinetics of cardiac troponin I (cTn-I) concentrations broken down by surgical procedure (on-pump vs off-pump) at baseline (0), 1 hour, 2 hours, 4 hours, 8 hours, 24 hours, 48 hours, and 72 hours, respectively. Dots represent the outliers that were outside the calculated range, possibly because of biologic variability. The 2 measurements differed significantly $(P=.001)$. The cTn-I concentration was significantly higher in the on-pump group than in the off-pump group at 1 hour $(P<.0001), 2$ hours $(P<.0001), 4$ hours $(P<.0001)$, 8 hours $(P<.0001)$, and 24 hours $(P=.04)$.

1114 The Journal of Thoracic and Cardiovascular Surgery • May 2008 


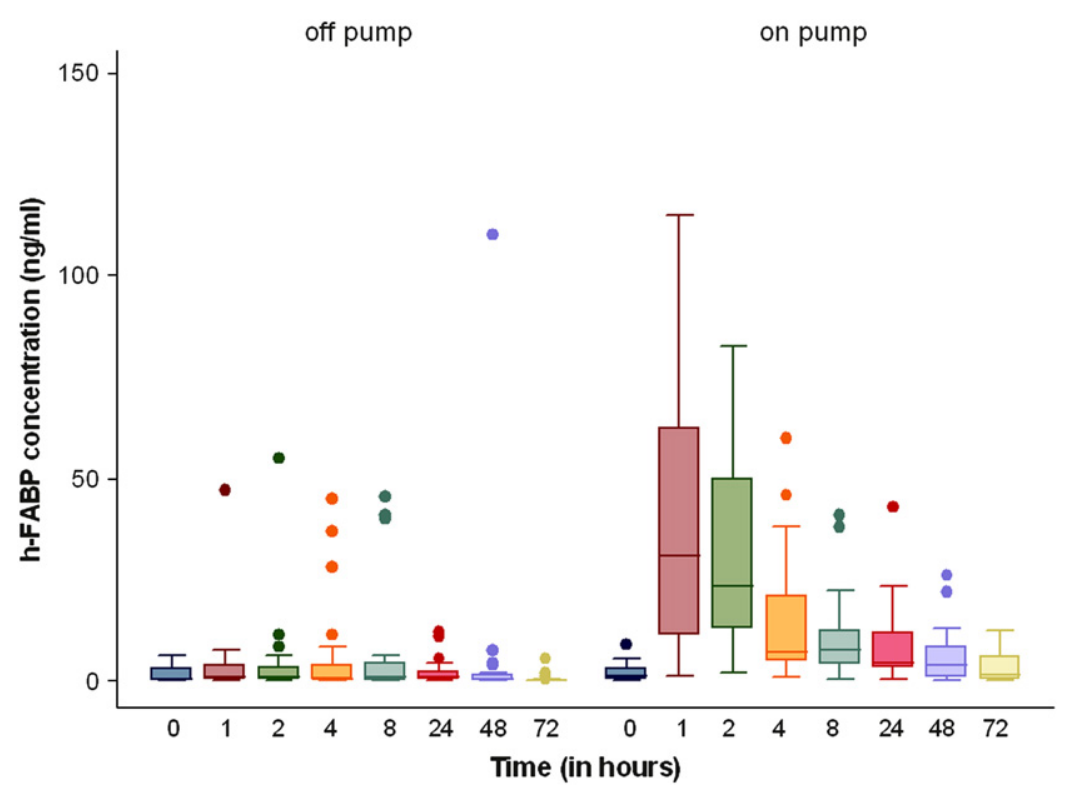

Figure 3. Release kinetics of heart-type fattyacid-binding-protein (h-FABP) concentrations broken down by surgical procedure (on-pump vs off-pump) at baseline (0), 1 hour, 2 hours, 4 hours, 8 hours, 24 hours, 48 hours, and 72 hours, respectively. Dots represent the outliers that were outside the calculated range, possibly because of biologic variability. The 2 measurements differed significantly ( $P<.0001)$. The hFABP concentration was significantly higher in the on-pump group than in the off-pump group at 1 hour $(P<$ $.0001), 2$ hours $(P=.001), 4$ hours $(P=.0002), 8$ hours $(P=.0008), 24$ hours $(P=.0002), 48$ hours $(P=.0004)$, and 72 hours $(P<.0001)$.

hFABP was the second-best diagnostic discriminator of perioperative myocardial injury, with an optimal cutoff value of greater than $6.8 \mathrm{ng} / \mathrm{mL}$ at 1 hour after aortic declamping (AUC, 0.94 [95\% CI, 0.88-1.00]; sensitivity, 88\%, specificity, 88\%; likelihood ratio [+], 7.33; Table E6 and Figure 6).

hs-CRP increase did not significantly separate patients undergoing postoperative CABG (on-pump) without myocardial injury. The optimally chosen cutoff values determined for hs-CRP, CK-MB, and myoglobin are presented in Table E6. In an attempt to predict the risk of myocardial injury after on-pump CABG by means of logistic regression analysis using each cardiac biomarkers revealed the following. Patients with increased hFABP levels of greater than $6.8 \mathrm{ng} / \mathrm{mL}$, cTn-I levels of greater than $0.92 \mathrm{ng} / \mathrm{mL}, \mathrm{CK}-\mathrm{MB}$ levels of greater than $48.9 \log$ units $/ \mathrm{mL}$, and myoglobin levels of greater than $176 \mu \mathrm{g} / \mathrm{mL}$ were at 53.77 (95\% CI, 9.76296.12) times, 132.25 (95\% CI, 17.14-1020.49) times, 6.61 (95\% CI, 1.92-22.72) times, and 10.02 (95\% CI, 2.7436.72 ) times higher risk of myocardial injury after on-pump CABG. Increased hs-CRP levels were nonpredictors of

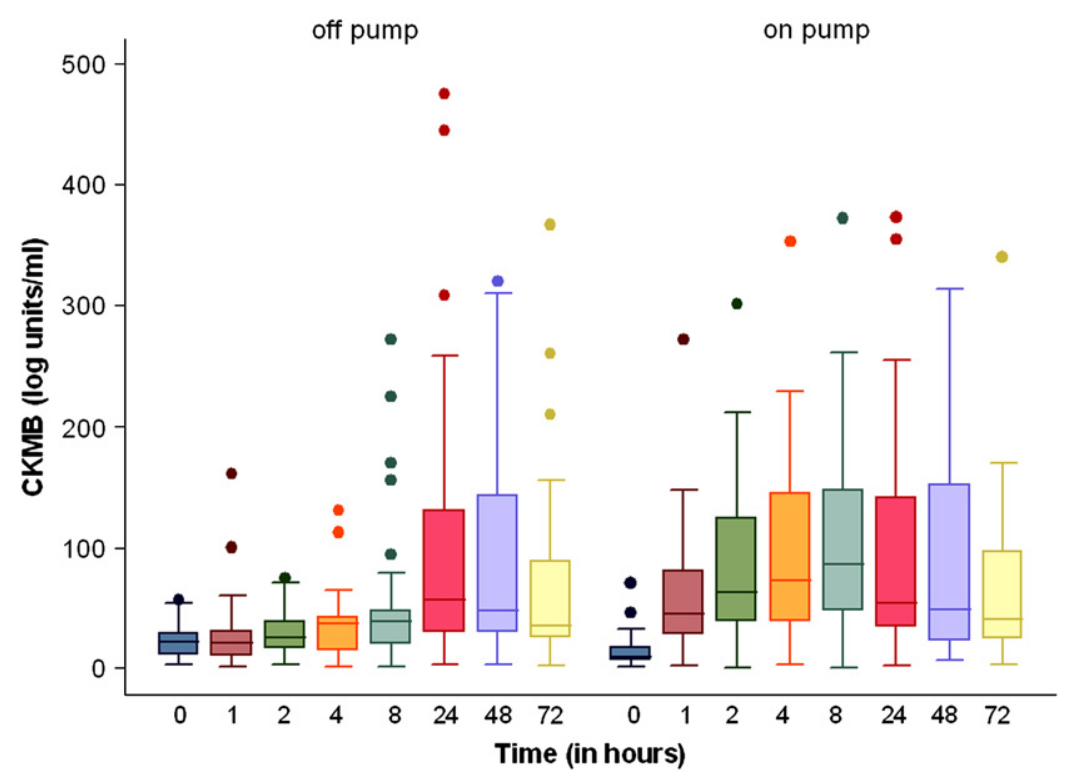

Figure 4. Release kinetics of creatine kinase-MB (CKMB) concentrations broken down by surgical procedure (on-pump vs off-pump) at baseline (0), 1 hour, 2 hours, 4 hours, 8 hours, 24 hours, 48 hours, and 72 hours, respectively. Dots represent the outliers that were outside the calculated range, possibly because of biologic variability. The degree of CK-MB increase was significantly higher in the on-pump group at 1 hour $(P=.001), 2$ hours $(P=.005)$, and 4 hours $(P=.0008)$ only.

The Journal of Thoracic and Cardiovascular Surgery • Volume 135, Number 51115 


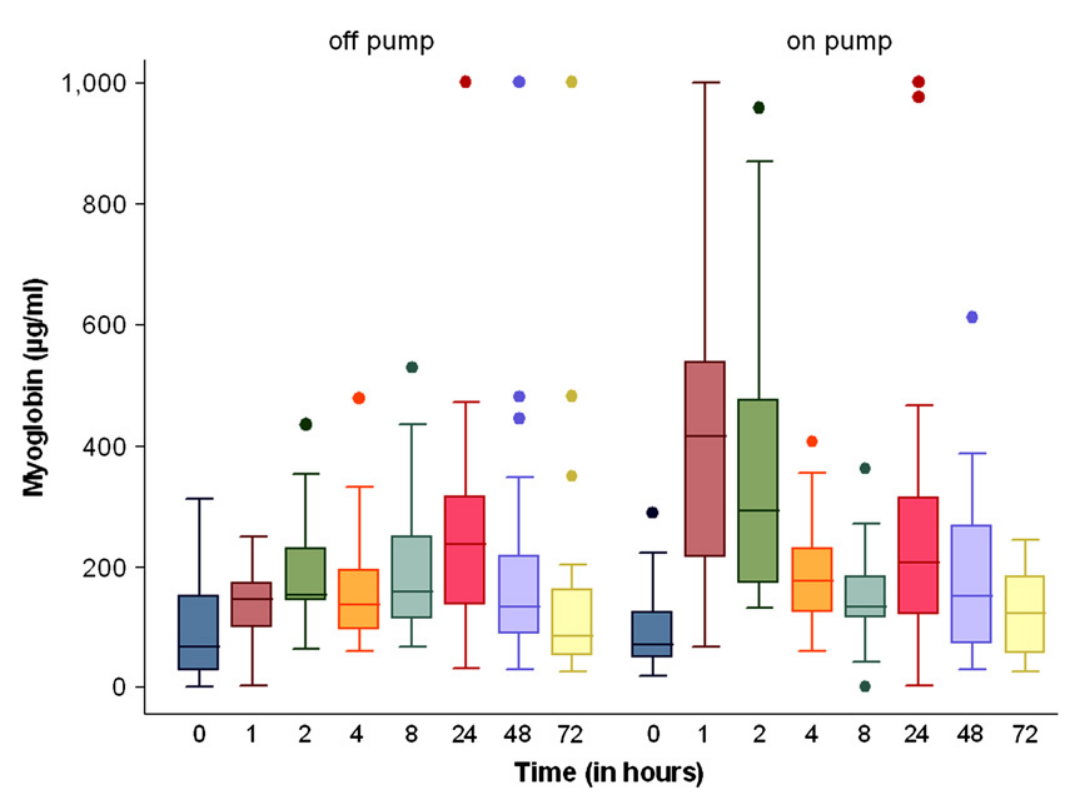

Figure 5. Release kinetics of myoglobin concentrations broken down by surgical procedure (onpump vs off-pump) at baseline (0), 1 hour, 2 hours, 4 hours, 8 hours, 24 hours, 48 hours, and 72 hours, respectively. Dots represent the outliers that were outside the calculated range, possibly because of biologic variability. The degree of myoglobin increase was significantly higher in the on-pump group at 1 hour $(P=.001)$ and 2 hours $(P=.04)$ only. myocardial injury in patients undergoing $\mathrm{CABG}$ with $\mathrm{CPB}$ (Table E6 and Figure 6).

\section{Discussion}

As far as we could establish, there are limited studies in the English-language literature addressing specifically the comparative release pattern and optimal cutoff values of different cardiac biomarkers, namely hs-CRP, cTn-I, hFABP, CK$\mathrm{MB}$, and myoglobin, for evaluating the degree of perioperative myocardial injury after surgical revascularization with or without CPB. ${ }^{1-5,8-14}$ The diagnostic discrimination limits of the cardiac biomarkers and the ability to predict the risk of myocardial injury after on-pump CABG by using the degree of increase of cardiac biomarker levels also have not been established. ${ }^{1-5,8-14}$

The major finding in this investigation was consistently higher increases of hs-CRP, cTn-I, hFABP, CK-MB, and myoglobin levels in the on-pump group than in the offpump group. The second important finding was identification of the best diagnostic discriminator of myocardial injury by using ROC curve analysis of all the cardiac biomarkers. The third important finding was the ability to predict the risk of myocardial injury after on-pump CABG by using the degree of increase of cardiac biomarkers, namely hFABP, cTn-I, CK$\mathrm{MB}$, and myoglobin. The increase of hs-CRP levels was a nonpredictor of myocardial injury after on-pump CABG.

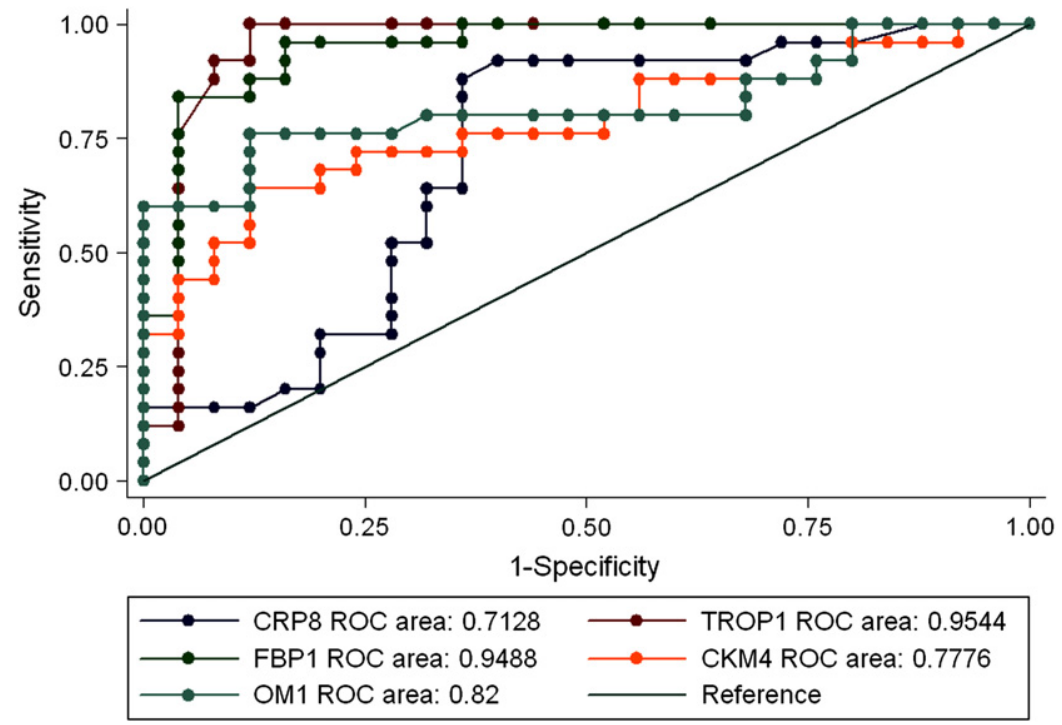

Figure 6. The receiver operating characteristic (ROC) curve of the study group to compare the tradeoffs between the true-positive rate and the false-positive rate of increase of all cardiac biomarker levels to identify all the diagnostic discrimination limits for each markers (high-sensitivity C-reactive protein, heart-type fatty acidbinding protein, cardiac troponin I, creatine kinase-MB, and myoglobin). Cardiac troponin I and heart-type fatty acid-binding protein were superior diagnostic discriminators of myocardial injury after on-pump coronary artery bypass grafting.

1116 The Journal of Thoracic and Cardiovascular Surgery • May 2008 
Cardiac Biomarkers: Characteristics and Practical Application for Detection of Myocardial Injury

Cardiospecific marker proteins are intracellular molecules soluble in cytoplasm or bound to subcellular structures that are released to the extracellular space after damage of the myocardial cell membrane. Plasma levels of specific marker proteins follow a typical pattern. Small water-soluble molecules are more rapidly washed out and detectable in the serum than proteins with a larger molecular mass, mainly because of the permeability of the endothelial layer. ${ }^{4,5,9,14,17}$

An ideal marker of myocardial injury would (1) be found in high concentrations in myocardium; (2) not be found in other tissues, even in trace amounts or under pathologic conditions; (3) be released rapidly and completely after myocardial injury; (4) be released in direct proportion to the extent of myocardial injury; and (5) persist in plasma for several hours to provide a convenient diagnostic time window but not so long that recurrent injury would not be identified. Thus markers with improved sensitivity and specificity are required for accurate and reliable information concerning myocardial biochemistry. ${ }^{4,5,9,14}$

$\mathrm{hFABP}$ is a water-soluble, small, intracellular protein consisting of 132 amino acid residues and weighing 14,500 d. Its physiologic role is the transport of hydrophobic long-chain fatty acids from the cell membrane to mitochondria to enter the citric acid cycle. After membrane damage, it is released to the extracellular space and, because of its small size, immediately enters the blood compartment. ${ }^{19,17-19}$

The published literature on the use of hFABP in cardiac surgical patients is limited, ${ }^{10,17-19}$ although it has been reported to be a highly sensitive marker of myocardial injury and perioperative myocardial ischemia. Petzold and coworkers ${ }^{10}$ investigated the release pattern of hFABP, CK$\mathrm{MB}$, and troponin I during conventional $\mathrm{CABG}$ at intervals of 5 and 60 minutes after declamping and 1,2, and 10 days thereafter. They concluded that hFABP is a rapid marker of myocardial damage and peaks earlier than CK-MB or troponin I. Hasegawa and colleagues ${ }^{18}$ evaluated hFABP and concluded that it might be a rapid and potentially useful prognostic indicator of myocardial damage and clinical outcome in pediatric cardiac surgery.

CRP is a 135,000-d nonimmunoglobulin protein having 5 identical subunits. ${ }^{4,9,14,20,21}$ Assay for C-reactive protein has a sensitivity of about $5 \mathrm{mg} / \mathrm{L}$. By using this assay, its level could be detected only when it is significantly increased. Recently available high-sensitivity assay of C-reactive protein (hs-CRP) using labeling of anti-CRP antibodies with another enzyme (enzyme-linked immunosorbent assay) or a fluorescent compound and attaching the antibody, either monoclonal or polyclonal, to polystyrene beads 1 to 6 allows measurement of a $\mathrm{C}$-reactive protein concentration as low as $0.15 \mathrm{mg} / \mathrm{L} .{ }^{20,21}$ To our knowledge, no studies have used hs-CRP to compare the degree of myocardial injury after revascularization with and without using $\mathrm{CPB}$.
Myoglobin is a low-molecular-weight heme protein $(17,800 \mathrm{~d})$ that is abundant in cardiac and skeletal muscles but not in smooth muscle. Thus it is a sensitive but not specific marker of acute myocardial infarction, requiring the exclusion of skeletal muscle injury. ${ }^{4,5,22}$ Myoglobin is rapidly released from the necrotic myocardium, with subsequent rapid renal clearance. Because of rapid kinetics, myoglobin can define the timing of myocardial events if frequent samples are obtained. ${ }^{4,5,22}$ Myoglobin is often detectable 2 hours after coronary occlusion, with peak levels occurring at 3 to 15 hours. A pattern of discontinuous release of myoglobin consisting of multiple peaks or the "staccato phenomenon" has been reported to occur in patients who have had acute myocardial infarction caused by coronary occlusion and reperfusion. ${ }^{23}$

For nearly 3 decades, MB isoenzymes of creatine kinase have been the molecular marker of choice for evaluation of patients with suspected acute myocardial infarction. CK isoenzymes are dimers composed of 39,000- to 42,000-d subunits synthesized in the cytosol of myocytes. CK isoenzymes are composed of two M-subunits (MMCK), two B-subunits (BBCK), or one $\mathrm{M}$ and one $\mathrm{B}$ subunit (MBCK). BBCK is the most abundant in the brain, MMCK in striated muscle, and MBCK in the heart. ${ }^{4,5,9}$ The disadvantage of CK-MB as a cytosolic marker of perioperative myocardial cellular injury compared with troponins is not only its lower sensitivity and specificity but also the short diagnostic window of approximately 24 hours. ${ }^{24}$

Troponins are regulatory proteins (I, C, or T) located in the striated muscle. They regulate actinomyosin interactions. cTn-I and cardiac troponin T have small cytosol distribution and are tightly complexed to the contractile apparatus. These are more specific markers of myocardial injury and have been shown to predict the risk of mortality and cardiac events in patients with unstable angina to estimate infarct size after reperfusion and lower release pattern in patients with off-pump CABG compared with on-pump CABG. ${ }^{4,5,8,9,11-14,24,25}$

\section{Diagnostic Performance of Different Cardiac Biomarkers: Clinical Implications and \\ Recommendations}

Perioperative myocardial infarction after CABG remains a serious complication with a high risk of early and late mortality, as well as poor long-term outcome. ${ }^{1-4,6,7}$ The reported incidence varies between $5 \%$ and $20 \%$ in different publications. ${ }^{1-4,6,7}$ However, its prevalence depends on the tests and diagnostic criteria used. Electrocardiographic criteria remain uncertain and lack diagnostic accuracy in both the early and late postoperative periods. The primary goal of postoperative biochemical monitoring of cardiac patients is to establish appropriate markers to detect early minor cardiac cellular injury to inhibit postoperative myocardial infarction and to exclude the existence of cardiac complications. Therefore diagnosis depends on assessment of plasma levels of cardiospecific marker proteins. ${ }^{1-14}$ 
The aim of this prospective randomized study was to determine the release kinetics of the cardiac biomarkers, (hsCRP, cTn-I, hFABP, CK-MB, and myoglobin) in on-pump and off-pump revascularization. With regard to preoperative and operative data, randomization created 2 equivalent groups for all the variables (Table E1).

Because the decision regarding the vessels to be grafted was made before randomization and in no case was the planned program aborted, the number of bypasses per patient was marginally different in both groups, including the number of arterial grafts $(3.2 \pm 0.62$ vs $3.1 \pm 0.60, P=.56)$. We concur with the observations of other investigators on the reduced requirement of inotropic support in patients undergoing revascularization without $\mathrm{CPB}$ compared with the onpump group $\left(P<.0001\right.$, Table E3) ${ }^{1-3}$

In this study there were consistently higher increases of all cardiac biomarkers in patients undergoing arrested-heart revascularization than in the beating-heart group. This indicates more myocardial injury despite optimal cardioprotection in the on-pump group compared with that in the off-pump group. A comparatively higher release of hFABP, cTn-I, and CK$\mathrm{MB}$ in patients undergoing on-pump CABG is probably because on-pump $\mathrm{CABG}$ results in global ischemia whereas off-pump CABG leads to localized ischemia.

Although the cutoff values of cardiac markers have been reported elaborately for patients presenting with chest pain, ${ }^{5,11,12,26}$ these values are not well established for assessment of myocardial injury in patients undergoing surgical revascularization with or without $\mathrm{CPB}$. Based on the data in the present study, we found optimal cutoff values and test characteristics of all available cardiac biomarkers using ROC curves in patients undergoing $\mathrm{CABG}$ with $\mathrm{CPB}$.

ROC analysis of cardiac biomarkers indicated cTn-I as the best diagnostic discriminator of myocardial injury, with an optimal cutoff value of greater than $0.92 \mathrm{ng} / \mathrm{mL}$ (AUC, 0.95 [95\% CI, 0.88-1.0]; sensitivity, 92\%; specificity, 92\%; likelihood ratio $[+], 11.50$; Table E6 and Figure 6). $\mathrm{hFABP}$ was the second-best diagnostic discriminator of perioperative myocardial injury, with an optimal cutoff value of greater than $6.8 \mathrm{ng} / \mathrm{mL}$ (AUC, 0.94 [95\% CI, 0.88-1.00]; sensitivity, $88 \%$; specificity, $88 \%$; likelihood ratio $[+]$, 7.33; Table E6 and Figure 6). hs-CRP increase did not significantly separate patients undergoing postoperative CABG (on-pump) with or without myocardial injury.

Thus in patients undergoing CABG with the potential for concomitant myocardial and skeletal muscle injury, the high cardiospecificity of hFABP and cTn-I could make these markers reliable tools in the diagnosis of perioperative myocardial injury and in comparison of different cardioplegia techniques.

ROC curve analysis of cardiac biomarkers indicated cTn-I and $\mathrm{hFABP}$ as the superior diagnostic discriminators of myocardial injury, with optimal cutoff values of greater than 0.92 $\mathrm{ng} / \mathrm{mL}$ at 1 hour after aortic declamping (AUC, 0.95 [95\% CI,
0.88-1.00]; sensitivity, 92\%; specificity, 92\%; likelihood ratio $[+], 11.50)$ and greater than $6.8 \mathrm{ng} / \mathrm{mL}$ at 1 hour after aortic declamping (AUC, 0.94 [95\% CI, 0.88-1.00]; sensitivity, $88 \%$; specificity, $88 \%$; likelihood ratio [+], 7.33). Logistic regression revealed patients with increased cTn-I values of greater than $0.92 \mathrm{ng} / \mathrm{mL}$ and $\mathrm{hFABP}$ levels of greater than $6.8 \mathrm{ng} / \mathrm{mL}$ were at 132.25 (95\% CI, 17.14-1020.49) times and 53.77 (95\% CI, 9.76-296.12) times higher risk of myocardial injury after on-pump CABG. Increased hs-CRP levels were nonpredictors of myocardial injury in patients undergoing CABG with CPB.

While analyzing the release kinetics of different marker proteins, we found that $\mathrm{hFABP}$ concentrations were significantly higher in every sample drawn from patients undergoing arrested-heart revascularization, whereas cTn-I concentrations were significantly higher only until the 8-hour mark. At 24, 48, and 72 hours, cTn-I concentrations were comparable in our 2 groups. Moreover, hFABP concentrations peaked earlier in both groups compared with cTn-I concentrations. It is noteworthy that the hs-CRP increase did not significantly separate patients undergoing postoperative CABG (onpump) with or without myocardial injury.

The above observations have important implications in the management of patients undergoing $\mathrm{CABG}$ with or without $\mathrm{CPB}$ in the early postoperative period. Although most patients have an uneventful postoperative period after CABG, irrespective of technique, and few have had clinically significant myocardial infarction, intensive care specialists are often confronted with a large group of patients whose clinical situations are borderline (nonspecific electrocardiographic changes and mild hypotension with or without inotropes). Release of hFABP could help identify those patients at an early stage who, because of cardiac damage, could benefit from prolonged monitoring in an ICU. Thus hFABP peaks earlier than cTn-I or hs-CRP/CK-MB. With the introduction of rapid assays, perioperative myocardial damage can be evaluated in the operating theater.

\section{Study Limitations}

Our study had its limitations in the evaluation of left ventricular function in the postoperative period. Transthoracic echocardiographic analysis might not be a sufficient tool for evaluation of left ventricular function because of a poor window in the immediate postoperative period. Radionuclide studies or magnetic resonance imaging (MRI) for assessment of left ventricular function would have consolidated our findings, and better distinction between the 2 groups could have been established.

Second, it is unknown whether this reduction in release of myocardial enzymes in the off-pump group is associated with reduced perioperative myocardial stunning (reversible) or necrosis (irreversible) because enzyme release might be partly due to increased turnover of cytoplasmic pools. A comparative quantification of myonecrosis in 
patients undergoing multivessel CABG with and without CPB using cine-MRI and contrast-enhanced MRI would have assessed the functional significance of these biochemical markers.

Third, when assessing the utility of a biochemical test, the ability to compare it with an established gold standard is paramount. Unfortunately, there is no easily applicable gold standard for the diagnosis of postoperative myocardial infarction. Like us, most authors used electrocardiographic criteria of newly developed Q-waves, left bundle branch block, ST-T changes, and/or echocardiographically detected and newly developed wall-motion abnormalities. Of note, electrocardiographic or echocardiographic changes would not allow the diagnosis of smaller or nontransmural infarcts to be tested.

\section{Conclusions}

We conclude that measurable transient subclinical cardiac damage exists during surgical revascularization, and this damage is greater with on-pump revascularization, despite advances in myocardial preservation and CPB conduction.

hFABP peaks earlier than cTn-I or CK-MB, and there was a trend toward hFABP and cTn-I being superior diagnostic discriminators of perioperative myocardial damage. Serial determination of serum hFABP and cTn-I values immediately after reperfusion in the early postoperative period are useful in rapid detection of perioperative myocardial injury. hs-CRP is an unreliable diagnostic discriminator of perioperative myocardial injury. The high cardiospecificity of hFABP and cTn-I could make these reliable diagnostic tools in the diagnosis of perioperative myocardial injury, the comparison of different myocardial preservation strategies, and further decisions about diagnostic and therapeutic options in these patients.

The authors are grateful to Mr. Shankar Sharma for preparation of the manuscript.

\section{References}

1. van Dijk D, Nierich AP, Jansen WL, et al. Early outcome after off-pump versus on-pump coronary bypass surgery. Results from a randomized study. Circulation. 2001;104:1761-6.

2. Calafiore AM, Di Mauro M, Contini M, et al. Myocardial revascularisation with and without cardiopulmonary bypass in multivessel disease: impact of the strategy on early outcome. Ann Thorac Surg. 2001;72:456-63.

3. Angelini GD, Taylor FC, Reeves BC, Ascione R. Early and midterm outcome after off-pump and on-pump surgery in beating heart against cardioplegic arrest studies (BHACAS 1 and 2): a pooled analysis of two randomized controlled trials. Lancet. 2002;359:1194-9.

4. Adams JE. Clinical application of markers of cardiac injury: basic concepts and new considerations. Clin Chim Acta. 1999;284:127-34.

5. Thielmann M, Massoudy P, Marggraf G, et al. Role of troponin I, myoglobin, and creatine kinase for the detection of early graft failure following coronary artery bypass grafting. Eur J Cardiothorac Surg. 2004;26:102-9.
6. Force T, Hibberd P, Week G, et al. Perioperative MI after CABG. Clinical significance and approach to risk stratification. Circulation. 1990; 82:903-12.

7. Comunale ME, Body SC, Ley C, et al. The concordance of intraoperative left ventricular wall-motion abnormalities and electrocardiographic ST-segment changes: association with outcome after coronary revascularization. Multicenter Study of Perioperative Ischemia (McSP) Research Group. Anesthesiology. 1998;88:945-54.

8. Bonnefoy E, Filley S, Kirkorian G, et al. Troponin I, troponin T or creatinine kinase-MB to detect perioperative myocardial damage after coronary artery bypass surgery. Chest. 1998;114:482-6.

9. Fransen EJ, Diris JHC, Maessen JG, et al. Evaluation of "new" cardiac markers for ruling out myocardial infarction after coronary artery bypass grafting. Chest. 2002;122:1316-21.

10. Petzold T, Feindt $P$, Sunderdiek U, et al. Heart type fatty acid binding protein (hFABP) in the diagnosis of myocardial damage in coronary artery bypass grafting. Eur J Cardiothorac Surg. 2001;19:859-64.

11. Carrier MPM, Perrault LP, Solymoss C, Pelleteir LC. Troponin levels in patients with myocardial infarction after coronary artery bypass grafting. Ann Thorac Surg. 2000;69:435-40.

12. Thielmann M, Massoudy P, Schmermund A, et al. Diagnostic discrimination between graft-related and non-graft-related perioperative myocardial infarction with cardiac troponin I after coronary artery bypass surgery. Eur Heart J. 2005;26:2440-7.

13. Alwan K, Falcoz PE, Alwan J, et al. Beating versus arrested heart coronary revascularization: evaluation by cardiac troponin I release. Ann Thorac Surg. 2004;77:2051-5.

14. Crescenzi G, Cedrati V, Landoni G, et al. Cardiac biomarker release after CABG with different surgical technique. J Cardiothorac Vasc Anesth. 2004; 18:34-7.

15. Rao V, Ivanov J, Weisel RD, et al. Predictors of low cardiac output syndrome after coronary artery bypass. J Thorac Cardiovasc Surg. 1996; 112:38-51.

16. Hanley JA, Mc Neil BJ. A method of comparing the areas under receiver operating characteristic curves derived from the same cases. Radiology. 1983;148:839-43.

17. Glatz JF, van der Vusse GJ, Simoons ML, et al. Fatty acid-binding protein and the early detection of acute myocardial infarction. Clin Chim Acta. 1998;272:87-92.

18. Hasegawa T, Yoshimura N, Oka S, et al. Evaluation of heart fatty acidbinding protein as a rapid indicator for assessment of myocardial damage in pediatric cardiac surgery. J Thorac Cardiovasc Surg. 2004;127: $1697-702$.

19. Suzuki K, Sawa Y, Kadoba K, et al. Early detection of cardiac damage with heart fatty acid-binding protein after cardiac operations. Ann Thorac Surg. 1998;65:54-8.

20. Borque L, Bellod L, Rus A, Seco ML, Galisteo-Gonzalez F. Development and validation of an automated and ultrasensitive immunoturbidimetric assay for C-reactive protein. Clin Chem. 2000;46: 1839-42.

21. Kapyaho K, Welin MG, Tanner P, et al. Rapid determination of C-reactive protein by enzyme immunoassay using two monoclonal antibodies. Scand J Clin Lab Invest. 1989;49:389-93.

22. Cairns JA, Missirlis E, Walker WHC. Usefulness of serial determinations of myoglobin and creatine kinase in serum compared for assessment of acute myocardial infarction. Clin Chem. 1983;29:469-73.

23. Gasser RNA, Hauptlorenz S, Dworzak E, et al. The typical staccato phenomenon of myoglobin in acute myocardial infarction disappears under thrombolytic treatment. Fibrinolysis. 1987;1:177-82.

24. Metzler H, Gries M, Rehak P, et al. Perioperative myocardial cell injury: the role of troponins. Br J Anaesth. 1997;78:386-90.

25. Newman MF. Troponin I in cardiac surgery: marking the future. Am Heart J. 2001;141:325-6.

26. Apple FS, Maturen AJ, Mullins RE, et al. Multicenter clinical and analytical evaluation of the AxSYM troponin-I immunoassay to assist in the diagnosis of myocardial infarction. Clin Chem. 1999;45: 206-12. 
TABLE E1. Baseline characteristics of the study group $(n=50)$

\begin{tabular}{lccc}
\hline \multicolumn{1}{c}{ Variables } & On-pump CABG & Off-pump CABG & P value \\
\hline No. of patients (\%) & $25(50 \%)$ & $25(50 \%)$ & - \\
Age (y), mean \pm SD (range) & $60.2 \pm 6.8(50-74)$ & $58.8 \pm 7.8(40-71)$ & .5 \\
Male population (n [\%]) & $21(84 \%)$ & $20(80 \%)$ & 1.00 \\
Weight (kg), mean \pm SD (range) & $65 \pm 5.8(46-84)$ & $61.8 \pm 6.2(47-83)$ & .06 \\
Height (cm), mean \pm SD (range) & $164.2 \pm 4.8(155-172)$ & $163.9 \pm 4.6(154-168)$ & .82 \\
Preoperative left ventricular ejection & $0.52 \pm 0.60(0.40-0.60)$ & $0.54 \pm 0.64(0.35-0.68)$ & .9 \\
$\quad$ fraction, mean \pm SD (range) & $2.8 \pm 0.6(2-3)$ & $2.8 \pm 0.4(1-3)$ & 1.00 \\
No. of diseased vessels, mean \pm SD (range) & $7(28 \%)$ & $8(32 \%)$ & .76 \\
Diabetes mellitus (n [\%]) & $14(56 \%)$ & $15(60 \%)$ & .77 \\
Hypertension (n [\%]) & $10(40 \%)$ & $11(44 \%)$ & .77 \\
Preoperative myocardial infarction (n [\%]) & $3(12 \%)$ & $9(36 \%)$ & 1.00 \\
Smoking (n [\%]) & & $22(88 \%)$ & 1.00 \\
Medications $\quad 23(92 \%)$ & $12(48 \%)$ & .77 \\
$\quad \beta$-adrenergic blockers (n [\%]) & $11(44 \%)$ & $25(100 \%)$ & 1.00 \\
Angiotensin-converting enzyme inhibitors (n [\%]) & $24(96 \%)$ & \\
Nitrates (n [\%]) & & & \\
\hline
\end{tabular}

Boldface indicates statistical significance, $C A B G$, Coronary artery bypass grafting; $S D$, standard deviation. 
TABLE E2. Perioperative variables of the study group

\begin{tabular}{lcrr}
\hline \multicolumn{1}{c}{ Variables } & On-pump CABG & Off-pump CABG & P value \\
\hline Total no. of distal anastomoses & $3.2 \pm 0.62$ & $3.1 \pm 0.60$ & .56 \\
Bypass conduit & & 22 & .46 \\
$\quad$ LITA (n) & 19 & 5 & 1.00 \\
$\quad$ Radial artery (n) & 4 & 0 & - \\
Perioperative MI & 0 & 0 & - \\
ST-T wave changes & 0 & 0 & - \\
Requirement for IABP & 0 & $12.80 \pm 2.42$ & $<.001$ \\
Duration of ventilation (h) & $18.60 \pm 3.62$ & $35.80 \pm 1.8$ & $<.001$ \\
ICU length of stay (h) & $41.28 \pm 0.62$ &
\end{tabular}

Boldface indicates statistical significance. CABG, Coronary artery bypass grafting; LITA, left internal thoracic artery; $M I$, myocardial infarction; IABP, Intraaortic balloon-pump, $I C U$, intensive care unit. 
TABLE E3. Inotropic drug requirement and postoperative left ventricular function of the study group

\begin{tabular}{|c|c|c|c|}
\hline Variables & On-pump CABG, no. (\%) & Off-pump CABG, no. (\%) & $P$ value \\
\hline \multicolumn{4}{|l|}{ Inotropic drug requirement } \\
\hline None (NTG or SNP) & $4(16 \%)$ & $18(72 \%)$ & \\
\hline Mild (dopamine $<5 \mu \mathrm{g} \cdot \mathrm{kg}^{-1} \cdot \min ^{-1}$ ) & $17(68 \%)$ & $7(28 \%)$ & $<.0001$ \\
\hline $\begin{array}{l}\text { Moderate (dopamine/dobutamine }>5 \mu \mathrm{g} \cdot \mathrm{kg}^{-1} \cdot \mathrm{min}^{-1} \\
\quad \text { or adrenaline }<0.1 \mu \mathrm{g} \cdot \mathrm{kg}^{-1} \cdot \mathrm{min}^{-1} \text { ) }\end{array}$ & $4(16 \%)$ & 0 & \\
\hline \multicolumn{4}{|l|}{ LV function at $8 \mathrm{~h}$} \\
\hline Moderate $(E F=0.30-0.50)$ & $24(96 \%)$ & $17(68 \%)$ & .023 \\
\hline Good $(E F>0.50)$ & $1(4 \%)$ & $8(32 \%)$ & \\
\hline \multicolumn{4}{|l|}{ LV function before discharge } \\
\hline Moderate $(E F=0.30-0.50)$ & $14(56 \%)$ & $12(48 \%)$ & .57 \\
\hline Good $(E F>0.50)$ & $11(44 \%)$ & $13(52 \%)$ & \\
\hline
\end{tabular}

Boldface indicates statistical significance. CABG, Coronary artery bypass grafting; NTG, nitroglycerin; SNP, sodium nitroprusside; $E F$, ejection fraction. 
TABLE E4A. Perioperative values of cardiac biomarkers after coronary artery bypass grafting performed with 2 different techniques at different time intervals: High-sensitivity C-reactive protein (mg/L)

\begin{tabular}{|c|c|c|c|}
\hline Time intervals (h) & $\begin{array}{c}\text { On-pump (group I), mean } \pm S D \\
\text { (range, median) }\end{array}$ & $\begin{array}{c}\text { Off-pump (group II), mean } \pm \text { SD } \\
\text { (range, median) }\end{array}$ & $P$ value \\
\hline Baseline & $3.78 \pm 2.74(0.3-10.8,3.1)$ & $4.2 \pm 2.95(0.6-10.2,2.7)$ & .76 \\
\hline 1 & $3.26 \pm 2.98(0.7-12.4,2.5)$ & $3.72 \pm 3.90(0.7-15.5,2.4)$ & .78 \\
\hline 2 & $2.65 \pm 2.73(0.5-10.4,1.5)$ & $2.57 \pm 2.80(0.2-12.4,1.8)$ & .80 \\
\hline 4 & $4.36 \pm 2.87(1.3-12.3,3.6)$ & $2.9 \pm 2.25(0.4-10.4,2.4)$ & .04 \\
\hline 8 & $6.6 \pm 2.9(2.1-12.8,6)$ & $4.6 \pm 3.36(1.2-10.9,2.6)$ & .009 \\
\hline 24 & $1.9 \pm 0.68(1-3,1.9)$ & $1.86 \pm 0.57(1-2.6,2)$ & .41 \\
\hline 48 & $2.31 \pm 0.92(1.1-4.5,2.2)$ & $1.96 \pm 0.68(0.2-2.7,2.2)$ & .26 \\
\hline 72 & $2.18 \pm 0.89(0.9-4.4,2.2)$ & $2.04 \pm 0.68(0.2-3.1,2.2)$ & .67 \\
\hline
\end{tabular}

Boldface indicates statistical significance. $S D$, Standard deviation. 
TABLE E4B. Perioperative values of cardiac biomarkers after coronary artery bypass grafting performed with 2 different techniques at different time intervals: Cardiac troponin I (ng/mL)

\begin{tabular}{|c|c|c|c|}
\hline Time intervals (h) & $\begin{array}{c}\text { On-pump (group I), mean } \pm \text { SD } \\
\text { (range, median) }\end{array}$ & $\begin{array}{c}\text { Off-pump (group II), mean } \pm \text { SD } \\
\text { (range, median) }\end{array}$ & $P$ value \\
\hline Baseline & $0.29 \pm 0.48(0-1.5,0.2)$ & $0.42 \pm 1.03(0.2-5.4,0.2)$ & .06 \\
\hline 1 & $3.02 \pm 3.13(0.5-14,2)$ & $0.49 \pm 1.02(0.2-5.3,0.2)$ & $<.0001$ \\
\hline 2 & $5.03 \pm 4.79(0-17,2.5)$ & $0.65 \pm 1.23(0.2-5.6,0.2)$ & $<.0001$ \\
\hline 4 & $8.9 \pm 7.5(1.2-28,5.5)$ & $1.05 \pm 1.86(0.2-7.5,0.36)$ & $<.0001$ \\
\hline 8 & $8.4 \pm 7.52(1.3-27.5,6)$ & $7.63 \pm 18.26(0.2-58,0.68)$ & $<.0001$ \\
\hline 24 & $3.45 \pm 3.87(0-18,2.1)$ & $13.75 \pm 29.03(0.2-94.8,0.98)$ & .04 \\
\hline 48 & $1.61 \pm 1.41(0-6,1)$ & $0.2 \pm 84.1(8.68-19.62,0.83)$ & .91 \\
\hline 72 & $0.83 \pm 0.86(0-3.5,0.69)$ & $6.24 \pm 13.79(0.2-56.4,0.4)$ & .47 \\
\hline
\end{tabular}

Boldface indicates statistical significance. $S D$, Standard deviation. 
TABLE E4C. Perioperative values of cardiac biomarkers after coronary artery bypass grafting performed with 2 different techniques at different time intervals: Heart-type fatty acid-binding protein $(\mathrm{ng} / \mathrm{mL})$

\begin{tabular}{|c|c|c|c|}
\hline Time intervals (h) & $\begin{array}{c}\text { On-pump (group I), mean } \pm \text { SD } \\
\text { (range, median) }\end{array}$ & $\begin{array}{c}\text { Off-pump (group II), mean } \pm \text { SD } \\
\text { (range, median) }\end{array}$ & $P$ value \\
\hline Baseline & $2.0 \pm 2.21(0.2-9,1.25)$ & $1.41 \pm 1.86(0.12-6.5,0.5)$ & .06 \\
\hline 1 & $43.52 \pm 36.76(1.2-115,31)$ & $3.80 \pm 9.29(0.2-47,1)$ & $<.0001$ \\
\hline 2 & $30.78 \pm 24.32(2-82.5,23.5)$ & $4.52 \pm 10.91(0.2-55,1)$ & .001 \\
\hline 4 & $14.72 \pm 15.14(1-60,7)$ & $6.2 \pm 12.06(0.13-45,0.6)$ & .0002 \\
\hline 8 & $10.14 \pm 10.4(0.31-41,7.5)$ & $6.5 \pm 13.61(0.12-45.5,0.8)$ & .0008 \\
\hline 24 & $7.94 \pm 9.20(0.31-43,4.5)$ & $2.51 \pm 3.64(0.2-12,0.8)$ & .0002 \\
\hline 48 & $5.87 \pm 6.67(0.25-26,4)$ & $5.54 \pm 21.83(0-110,0.5)$ & .0004 \\
\hline 72 & $3.49 \pm 3.53(0.1-2.5,1.6)$ & $0.47 \pm 1.17(0-5.5,0)$ & $<.0001$ \\
\hline
\end{tabular}

Boldface indicates statistical significance. $S D$, Standard deviation. 
TABLE E4D. Perioperative values of cardiac biomarkers after coronary artery bypass grafting performed with 2 different techniques at different time intervals: Creatine kinase-MB (log units $/ \mathrm{mL}$ )

\begin{tabular}{|c|c|c|c|}
\hline Time intervals (h) & $\begin{array}{c}\text { On-pump (group I), mean } \pm \text { SD } \\
\text { (range, median) }\end{array}$ & $\begin{array}{c}\text { Off-pump (group II), mean } \pm \text { SD } \\
\text { (range, median) }\end{array}$ & $P$ value \\
\hline Baseline & $15.83 \pm 16.31(1.3-70,9)$ & $22.07 \pm 14.96(38-57,21.3)$ & .08 \\
\hline 1 & $63.01 \pm 57.40(2.4-272,45.5)$ & $29.99 \pm 35.27(1.5-161,2)$ & .001 \\
\hline 2 & $83.46 \pm 70.61(0.6-301)$ & $10.62 \pm 19.72(3.4-74.5,25)$ & .005 \\
\hline 4 & $100.13 \pm 81.69(2.9-353,73)$ & $36.04 \pm 31.35(1.2-131,36.9)$ & .0008 \\
\hline 8 & $107.27 \pm 90.39(0-372,86)$ & $60.47 \pm 70.51(1.4-272,384)$ & .12 \\
\hline 24 & $100.17 \pm 106.70(1.6-373,54.1)$ & $110.78 \pm 130.36(2.8-475,56.7)$ & .86 \\
\hline 48 & $88.38 \pm 81.82(6.9-314,48.9)$ & $96.75 \pm 93.73(3.2-320,478)$ & .89 \\
\hline 72 & $72.75 \pm 72.95(3.3-340,40)$ & $75.20 \pm 86.91(1.7-367,35.1)$ & .81 \\
\hline
\end{tabular}

Boldface indicates statistical significance. $S D$, Standard deviation. 
TABLE E4E. Perioperative values of cardiac biomarkers after coronary artery bypass grafting performed with 2 different techniques at different time intervals: Myoglobin $(\mu \mathrm{g} / \mathrm{mL})$

\begin{tabular}{lccc}
\hline Time intervals $(\mathbf{h})$ & $\begin{array}{c}\text { On-pump (group I), mean } \pm \text { SD } \\
\text { (range, median) }\end{array}$ & $\begin{array}{c}\text { Off-pump (group II), mean } \pm \text { SD } \\
\text { (range, median) }\end{array}$ \\
\hline Baseline & $96.95 \pm 70.08(19.1-289,71.3)$ & $90.18 \pm 75.96(1.1-311,67.9)$ \\
1 & $399.66 \pm 262.22(67-1000,416)$ & $135.94 \pm 70.77(3.2-249,147)$ & .42 \\
2 & $349.48 \pm 234.71(131-957,293)$ & $191.40 \pm 90.69(64.4-434,154)$ & .001 \\
4 & $186.32 \pm 87.96(60.8-407,176)$ & $166.58 \pm 101.48(59.8-477,137)$ \\
8 & $152.14 \pm 79.03(1.3-362,134)$ & $196.03 \pm 115.18(66.6-528,159)$ \\
24 & $272.51 \pm 245.46(2.6-1000,207)$ & $258.98 \pm 191.29(32-1000,238)$ & .04 \\
48 & $183.15 \pm 138.81(30-611,152)$ & $203.85 \pm 203.87(30-1000,133)$ \\
72 & $119.21 \pm 72.62(26-244,123)$ & $156.24 \pm 204.06(26.7-480,85.8)$ \\
\hline
\end{tabular}

Boldface indicates statistical significance. $S D$, Standard deviation. 
TABLE E5. Area under the ROC curves and optimal cutoff values for each cardiac marker at every postoperative time point in patients undergoing CABG in the study group (on-pump) and the likelihood ratio

\begin{tabular}{|c|c|c|c|c|c|c|}
\hline Marker & $\begin{array}{l}\text { Time (h) after } \\
\text { arrival at ICU }\end{array}$ & $\begin{array}{l}\text { Cutoff } \\
\text { value }\end{array}$ & $\begin{array}{c}\text { Area under ROC } \\
\text { curve }(95 \% \mathrm{Cl})\end{array}$ & $\begin{array}{c}\text { Sensitivity } \\
(\%)\end{array}$ & $\begin{array}{c}\text { Specificity } \\
(\%)\end{array}$ & $\begin{array}{c}\text { Likelihood } \\
\text { ratio }(+)\end{array}$ \\
\hline \multirow[t]{7}{*}{ High- sensitivity C-reactive protein (mg/L) } & 1 & $\geq 2.5$ & $0.52(0.36-0.68)$ & 56 & 56 & 1.27 \\
\hline & 2 & $\geq 1.6$ & $0.52(0.35-0.68)$ & 48 & 48 & 0.92 \\
\hline & 4 & $\geq 2.9$ & $0.66(0.51-0.82)$ & 64 & 64 & 1.77 \\
\hline & 8 & $\geq 5.6$ & $0.71(0.56-0.86)$ & 64 & 64 & 1.77 \\
\hline & 24 & $\geq 2.0$ & $0.56(0.40-0.73)$ & 48 & 48 & 0.92 \\
\hline & 48 & $\geq 2.3$ & $0.59(0.42-0.75)$ & 48 & 56 & 1.09 \\
\hline & 72 & $\geq 2.2$ & $0.53(0.36-0.70)$ & 52 & 48 & 1.00 \\
\hline \multirow[t]{7}{*}{ Cardiac troponin I (ng/mL) } & 1 & $\geq 0.92$ & $0.95(0.88-1.00)$ & 92 & 92 & 11.50 \\
\hline & 2 & $\geq 1.2$ & $0.91(0.81-1.00)$ & 84 & 88 & 7.00 \\
\hline & 4 & $\geq 2.1$ & $0.94(0.87-1.00)$ & 88 & 88 & 7.33 \\
\hline & 8 & $\geq 2.9$ & $0.84(0.70-0.97)$ & 84 & 84 & 5.25 \\
\hline & 24 & $\geq 1.7$ & $0.66(0.49-0.83)$ & 68 & 68 & 2.12 \\
\hline & 48 & $\geq 0.9$ & $0.50(0.33-0.68)$ & 76 & 52 & 1.58 \\
\hline & 72 & $\geq 1.4$ & $0.44(0.27-0.61)$ & 52 & 56 & 1.18 \\
\hline \multirow[t]{7}{*}{ Heart-type fatty acid-binding protein $(\mathrm{ng} / \mathrm{mL})$} & 1 & $\geq 6.8$ & $0.94(0.88-1.00)$ & 88 & 88 & 7.33 \\
\hline & 2 & $\geq 6.5$ & $0.91(0.83-0.99)$ & 80 & 84 & 5.00 \\
\hline & 4 & $\geq 5.0$ & $0.81(0.68-0.94)$ & 76 & 80 & 3.80 \\
\hline & 8 & $\geq 4.5$ & $0.77(0.63-0.91)$ & 68 & 72 & 2.42 \\
\hline & 24 & $\geq 3.0$ & $0.80(0.67-0.92)$ & 76 & 76 & 3.16 \\
\hline & 48 & $\geq 1.4$ & $0.79(0.66-0.92)$ & 72 & 72 & 2.57 \\
\hline & 72 & $\geq 0.6$ & $0.82(0.71-0.94)$ & 80 & 80 & 4.0 \\
\hline \multirow[t]{7}{*}{ Creatine kinase MB (log units/mL) } & 1 & $\geq 30.0$ & $0.75(0.62-0.89)$ & 68 & 68 & 2.12 \\
\hline & 2 & $\geq 38.9$ & $0.76(0.62-0.90)$ & 76 & 76 & 3.16 \\
\hline & 4 & $\geq 42.9$ & $0.77(0.64-0.90)$ & 72 & 72 & 2.57 \\
\hline & 8 & $\geq 48.03$ & $0.70(0.55-0.86)$ & 76 & 76 & 3.16 \\
\hline & 24 & $\geq 56.7$ & $0.48(0.32-0.64)$ & 48 & 48 & 0.9 \\
\hline & 48 & $\geq 70.7$ & $0.48(0.32-0.65)$ & 52 & 52 & 1.08 \\
\hline & 72 & $\geq 40.6$ & $0.52(0.35-0.68)$ & 48 & 52 & 1.00 \\
\hline \multirow[t]{7}{*}{ Myoglobin $(\mu \mathrm{g} / \mathrm{mL})$} & 1 & $\geq 176$ & $0.82(0.69-0.94)$ & 76 & 76 & 3.16 \\
\hline & 2 & $\geq 196$ & $0.72(0.58-0.87)$ & 68 & 68 & 2.12 \\
\hline & 4 & $\geq 173$ & $0.59(0.43-0.76)$ & 56 & 56 & 1.27 \\
\hline & 8 & $\geq 157$ & $0.40(0.24-0.56)$ & 44 & 44 & 0.78 \\
\hline & 24 & $\geq 244$ & $0.47(0.30-0.63)$ & 44 & 44 & 0.78 \\
\hline & 48 & $\geq 166$ & $0.49(0.32-0.66)$ & 50 & 52 & 1.04 \\
\hline & 72 & $\geq 123$ & $0.50(0.34-0.67)$ & 56 & 56 & 1.27 \\
\hline
\end{tabular}

Boldface indicates statistical significance. $R O C$, Receiver operating characteristic; $C A B G$, coronary artery bypass grafting; ICU, intensive care unit; $C l$, confidence interval. 
TABLE E6. Risk of myocardial injury after on-pump CABG surgery by means of logistic regression by using each of the cardiac biomarkers

\begin{tabular}{|c|c|c|c|c|c|c|}
\hline Cardiac biomarkers & Time (h) & $\begin{array}{l}\text { Cutoff } \\
\text { value }\end{array}$ & $\begin{array}{c}\text { On-pump, } \\
\text { no. (\%) }\end{array}$ & $\begin{array}{c}\text { Off-pump, } \\
\text { no. }(\%)\end{array}$ & OR $(95 \%$ CI) & $P$ value \\
\hline \multirow[t]{2}{*}{ High- sensitivity C-reactive protein (mg/L) } & \multirow[t]{2}{*}{8} & $\geq 5.6$ & 95 & 79 & \multirow[t]{2}{*}{$3.16(0.99-10.03)$} & \multirow[t]{2}{*}{.05} \\
\hline & & $\leq 5.6$ & 80 & 96 & & \\
\hline \multirow[t]{2}{*}{ Cardiac troponin I (ng/mL) } & \multirow[t]{2}{*}{1} & $\geq 0.92$ & 129 & 46 & \multirow[t]{2}{*}{$132.25(17.14-1020.49)$} & \multirow[t]{2}{*}{$<.0001$} \\
\hline & & $\leq 0.92$ & 40 & 135 & & \\
\hline \multirow[t]{2}{*}{ Heart-type fatty acid-binding protein $(\mathrm{ng} / \mathrm{mL})$} & \multirow[t]{2}{*}{1} & $\geq 6.8$ & 138 & 40 & \multirow[t]{2}{*}{$53.77(9.76-296.12)$} & \multirow[t]{2}{*}{$<.0001$} \\
\hline & & $\leq 6.8$ & 37 & 138 & & \\
\hline \multirow[t]{2}{*}{ Creatine kinase-MB (log units $/ \mathrm{mL}$ ) } & \multirow[t]{2}{*}{4} & $\geq 42.9$ & 112 & 63 & \multirow[t]{2}{*}{$6.61(1.92-22.72)$} & \multirow[t]{2}{*}{.003} \\
\hline & & $\leq 42.9$ & 65 & 110 & & \\
\hline \multirow[t]{2}{*}{ Myoglobin $(\mu \mathrm{g} / \mathrm{mL})$} & \multirow[t]{2}{*}{1} & $\geq 176$ & 87 & 70 & \multirow[t]{2}{*}{$10.02(2.74-36.72)$} & \multirow[t]{2}{*}{$<.001$} \\
\hline & & $\leq 176$ & 87 & 105 & & \\
\hline
\end{tabular}

Boldface indicates statistical significance. $C A B G$, Coronary artery bypass grafting; $O R$, odds ratio; $C l$, confidence interval. 